\title{
Flow Behavior Simulation with Computational Fluid Dynamics in Spray Tower Scrubber
}

\author{
Majid Bayatian, Mohammad Reza Ashouri, and Rouhallah Mahmoudkhani
}

\begin{abstract}
Computational Fluid Dynamics (CFD) uses numerical methods and algorithms to solve and analyze problems that involve fluid flows. This paper describes the application of a commercial CFD code, to Simulation of Flow Behavior within Spray Tower Scrubber, focusing on silica particles. First a ventilation system was designed and constructed for pilot study. It was designed according to velocity pressure method balanced system design stated by VS-15-01 recommendation offered by ACGIH. Fluent package of Ansys, Inc is used to model and simulate this problem. Efficiency of inhalable pollutant particle collection has increased $(P-$ Value $<0.05)$ with the increase of the flow rate. Also, with increase in the flow rate, collection efficiency of particles was increases $(P$-Value $<0.05)$. From the simulation experimentations, the residuals do a very good job of converging at approximately 2460 iterations at inlet velocities of $11.176 \mathrm{~m} / \mathrm{s}$. In general, the CFD simulation can improve efficiency, reduce cost, and shorten experimental periods. It can also provide insights for optimal equipment design. With the increase of water flow rate the collection efficiency of inhalable and non-inhalable particles of silica particles increases. This is due to the increase of surface contact of water droplets with pollutant, which has caused the efficiency of the system. Future work should focuses on an improved prediction of droplet size distribution in order to enhance dust-capturing calculation.
\end{abstract}

Index Terms-Silica, CFD, spray tower scrubber.

\section{INTRODUCTION}

Using local ventilation systems is common for pollutants collection in industrial environments. Pollutant particles collected by the ventilation systems should be monitored, and the air exited from the stack should consist of pollutants less than the admissible amount offered by environmental protection agency. Therefore, due to the concern of environmental protection agency on air pollution and controlling it, using air pollution collector becomes more important. So, on one hand, for environmental protection and pollution collected by industries, and health care of the workers from the other, using a system that can collect pollution with high efficiency is necessary [1].

Computational Fluid Dynamics (CFD), a branch of fluid mechanics, uses numerical methods and algorithms to solve and analyze problems that involve fluid flows. It is widely applied to different fields such as combustion, airplane design, air pollution control and etc. By far CFD has been also applied to reactor modeling in chemical engineering field [2]. This approach enables performing full

Manuscript received April 2, 2015; revised June 8, 2015

The authors are with the Department of Public Health, Tehran medical sciences branch Islamic Azad University, Teheran, Iran (e-mail: majid_bayatian@yahoo.com, mahmoodkhany@yahoo.com). three-dimensional analysis, and predicting velocity, temperature, and concentration fields in the integration domain. While this procedure might ensure more detailed results, it requires a large amount of resources both in terms of CPU time and analysts' skills [3].

Particular attention has to be paid in CFD simulations to turbulence modeling. The effect of turbulent fluctuations can be modeled by the RANS (Reynolds averaged Navier-Stokes) approach, or fully simulated by direct numerical simulation (DNS). The DNS places very large demands on resources and, nowadays, is applied only to very simple cases. An intermediate solution is to use large eddy simulations (LES) that simulate only larger eddies and use models for simulating the effects of isotropic dissipating eddies. Although LES is less demanding than DNS, it is still quite demanding in complex scenarios. Consequently, RANS remains a good compromise between result accuracy and computational efforts. The most popular closure model for turbulence effects in the frame of the RANS approach is the $\mathrm{k}-\varepsilon$ two-equation model, since it ensures reasonable results and good stability [3].

There are many simulation softwares used in industry area, such as HYSIS, ASPEN PLUS, and ANSYSc. Different software has their advantage in different area. Fluent is a general purpose CFD code that has been in use since 1983. It was mainly applied to simulate complex fluid flow problems. It is especially appropriate for simulating the complex physics process [4].

Silica has different uses in industry, such as glasswork, ceramic, and etc. The major use of this matter in industry, and its hazard to human health, leads to effective control plans for the collection of air dispersed particles. One of the devices which can be used for the pollution of this particle is the scrubber [5].

The scrubbing process is a unit operation in which one or more components of a gas stream are selectively absorbed into an absorbent. Scrubbing is commonly encountered when treating flue gas (or some other polluted gas stream) to control acid gases, particulates, heavy metals, traces organics, and odors. Often, a scrubbing system is composed of two or more scrubbers in series. Although the most common name for such a unit operation installation is a scrubber or absorber, other names commonly used to reference such installations in industry are spray towers and packed or plate columns. It should be noted that the latter three unit operations may operate slightly differently from the wet and dry scrubbers (absorbers) defined here. These terms are mentioned here, because they are sometimes used interchangeably with mass transfer unit operations [6].

This paper describes the application of a commercial CFD code, to simulation of flow behavior within spray tower 
scrubber, focusing on silica particles. The capabilities of the models are assessed through comparisons with experimental data.

\section{MATERIAL AND METHODS}

\section{A. Experimental Setup}

In order to perform the experiments, first a ventilation system was designed and constructed for pilot study. It was designed according to velocity pressure method balanced system design stated by VS-15-01 recommendation offered by ACGIH [7]. The most important characteristic and detriment for determination of scrubber's dimension are air velocity and flow rate. Since, it is recommended to have an air velocity of 200-250 fpm inside the scrubber, according to $\mathrm{Q}=\mathrm{AV}$ equation the cross section area of scrubber, therefore according to Eq. 1 the diameter of the scrubber was calculated [8].

$$
A=\frac{\pi}{4} d^{2} \rightarrow d=2 \sqrt{\frac{A}{\pi}}
$$

Also, since it is recommended to have a height 2-2.5 times more than the diameter in scrubbers, after calculating the diameter of the scrubber according to Eq. 1, the height will also be calculated. Recommended limit for nozzles flow rate of spray tower scrubbers is equivalent to 5-15 gallon per each $1000 \mathrm{cfm}$ and according to the air flow rate recommended by ACGIH, the minimum and maximum needed water flow rate was calculated, therefore the pump was chosen in this regard. Since in this system the pollutant is particle, and these particles might deposition in the fan and cause imbalance, radial fan was used [9]. For determining the technical characteristics of the fan, Fanox software was used. In order to evaluate drop pressure, and as a result of actual velocity in the pilot system, pitot pipe was used. Also, the measurement place of drop pressure was determined according to the recommendations made by EPA. The air velocity in the duct was calculated in relation to the calculated drop pressure of the system by pitot pipe and Eq.2. Later, the diameter of the prop was determined with regard to the isokinetic conditions [7].

$$
V=4005 \sqrt{V P}
$$

We take 72 samples (36 samples before the collector and 36 after the collector) for determination of efficiency scrubber. The analysis was done based on the gravity and, we used from Eq3 to calculate the efficiency of the collection by the scrubber.

$$
R a=\frac{a-b}{a} \times 100
$$

In which, $a$ is the concentration before collector, $b$ the concentration after collector and $R a$ the collection efficiency. Also, SPSS software was used for data analysis.

\section{B. Mathematical Modeling}

The appropriate governing equations for the gas flow are the incompressible Nervier Stokes Equation (NSE) for a single phase flow obtained from the conservation of mass and momentum described by Caiting et al. [10].

Continuity equation:

$$
\frac{\partial\left(U_{i}\right)}{\partial x_{i}}=0
$$

Momentum equation:

$$
\frac{\rho_{g} \partial\left(U_{g}^{i} U_{g}^{j}\right)}{\partial x_{i}}=-\frac{\partial P}{\partial x_{i}}+\frac{\partial}{\partial x_{j}}\left[\mu_{e f f}\left(\frac{\partial U_{g}^{i}}{\partial x_{j}}+\frac{\partial U_{g}^{j}}{\partial x_{i}}\right)\right]+\rho_{g} g_{i}
$$

where, $i$ and $j$ are the direction vectors for the three coordinates $\left(x, y\right.$, and $z$ ) while $U^{i}$ and $U^{j}$ are the three velocity components $(u, v, w)$ of the gas flow, $\mu_{\text {eff }}$ is the effective dynamic viscosity of gas, $\rho_{g}$ is the gas density, $P$ is the gas pressure and $\rho_{g i}$ is the gas volume force in $i$-direction respectively. To avoid the unnecessary consumption of the computer time for the solution of the full-scale, turbulence model for should be considered.

Averaging is often used to simplify the solution of the governing equations of turbulence, but models are needed to represent scales of the flow that are not resolved. One of the most effective viscosity models for the simulations of the turbulent flow is the Harlow-Nakayama k- $\varepsilon$ model of the turbulent flow described in 6 and 7 equation. The model provides the time-averaged values of velocities and pressure of the gas or air throughout the system.

$k$-equation:

$$
\begin{gathered}
\rho \frac{\partial\left(k U_{i}\right)}{\partial x_{i}}+\rho U_{j} \frac{\partial k}{\partial x_{j}}=\frac{\partial}{\partial x_{i}}\left[\left(\mu+\frac{\mu_{t}}{\delta_{k}}\right) \frac{\partial k}{\partial x_{i}}\right]+\mu_{t} \frac{\partial U_{j}}{\partial x_{j}}\left(\frac{\partial U_{i}}{\partial x_{j}}+\right. \\
\partial U j \partial x i-\rho \varepsilon
\end{gathered}
$$

$\varepsilon$-equation:

$$
\rho \frac{\partial\left(\varepsilon U_{i}\right)}{\partial x_{i}}=\frac{\partial\left[\left(\mu+\frac{\mu_{t}}{\delta_{\varepsilon}}\right) \frac{\partial \varepsilon}{\partial x_{i}}\right]}{\partial x_{i}}+\frac{c_{1} \varepsilon}{k} \mu_{t} \frac{\partial U_{i}}{\partial x_{j}}\left(\frac{\partial U_{i}}{\partial x_{j}}+\frac{\partial U_{j}}{\partial x_{i}}\right)-c_{2} \rho \frac{\varepsilon^{2}}{k}
$$

where $k$ is the turbulent kinetic energy, $\varepsilon$ is the turbulent kinetic energy dissipation rate; $\mu_{t}$ is viscosity coefficient of turbulent flow while $\delta_{k}, \delta_{\varepsilon}, c_{1}, c_{2}$ are constants; $c_{1}=1.44, c_{2}=$ $1.92, \delta_{k}=1.0, \delta_{\varepsilon}=1.3[10]$. The standard $k-\varepsilon$ model was based on the hypothesis of the isotropic eddy-viscosity, which was modeled through the flow fields of the turbulent kinetic energy and the specific dissipation rate.

Fluent package of Ansys, Inc is used to model and simulate this problem. This package includes: Fluent, the solver, GAMBIT, the pre-processor for geometry modeling and mesh generation [11]. The mesh generated using the software GAMBIT, consists of around 14661 nodes. The simulations of the spreading gas were performed on an Intel ${ }^{\circledR}$ Core computer. A relative residual reduction factor of $10^{-5}$ was used as the convergence criterion for the conservation equations. It is assumed that isothermal condition prevails throughout the period of simulation.

\section{RESULTS}

\section{A. Experimental Setup}

First, flow rate and velocity air in system was determinate 
according to the recommendation of ACGIH, later the calculation sheet of the ventilation system was completed, and finally the height and diameter of the scrubber was calculated.

$$
\begin{gathered}
Q=A V \rightarrow 508=240 A \\
d=1.64 f t=0.5 m \\
h=2.5 \times 0.5=1.24 m
\end{gathered}
$$

With regard to the achieved flow rate the needed minimum and maximum water flow rate was 9.54 and 28.84 liters per minute, but after installation of the system and use of nozzles due to their drop pressure, according to the performed calculations and experiments the maximum flow rate of water was 20.3liters per minute. According to these results, the needed flow rates for this experiment were chosen 20.3 and 11.4 liter per minute. According to Eq. 2, and the measurement of drop pressure by pitot pipe, the actual velocity in the duct was made $2200 \mathrm{fpm} \mathrm{[12].}$

The sampling pump flow rate was chosen 2 liters per minute, and with regard to isokinetic condition, the diameter of the prop sample become:

$$
\begin{gathered}
V=2200 \mathrm{fpm} \times 0.00508=11.176 \frac{\mathrm{m}}{\mathrm{s}} \\
A=2.982 \times 10^{-6} \rightarrow d=2 \mathrm{~mm}
\end{gathered}
$$

Table I shows the concentration of inhalable and

\begin{tabular}{|c|c|c|c|}
\hline & variable & $20.3^{\mathrm{Lit}} / \mathrm{min}$ & $11.4^{\mathrm{Lit}} / \mathrm{min}$ \\
\hline \multirow[t]{3}{*}{ inhalable } & $\begin{array}{l}\text { Concentration mean } \\
\text { before collector }\end{array}$ & $347 \pm 27.1$ & $324 \pm 32.6$ \\
\hline & $\begin{array}{l}\text { Concentration mean } \\
\text { after collector }\end{array}$ & $138 \pm 12.3$ & $161 \pm 15.6$ \\
\hline & Efficiency $(\%)$ & 60.23 & 50.27 \\
\hline \multirow[t]{3}{*}{ non-inhalable } & $\begin{array}{l}\text { Concentration mean } \\
\text { before collector }\end{array}$ & $318 \pm 21.3$ & $327 \pm 22.8$ \\
\hline & $\begin{array}{l}\text { Concentration mean } \\
\text { after collector }\end{array}$ & $23 \pm 4.1$ & $33 \pm 6.3$ \\
\hline & Efficiency(\%) & 93 & 90 \\
\hline
\end{tabular}
non-inhalable silica particles \& collection efficiency. Table II shows the results from the experiment using Man-Whitney test among the studied parameters.

TABLE I: MEAN AND STD DEVIATION OF SILICA PARTICLES BEFORE AND

TABLE II: COLLECTION EFFICIENCY OF INHALABLE AND NON-INHALABLE SILICA PARTICLES

\begin{tabular}{lcc}
\hline \hline Pollutant & Water flow ${ }^{\mathrm{Lit}} / \mathrm{min}$ & Efficiency $(\%)$ \\
\hline Inhalable particles $^{1}$ & 20.3 & 60.23 \\
& 11.4 & 50.27 \\
Non-inhalable particles $^{2}$ & 20.3 & 93 \\
\hline \hline 1- $P$-Value is $0.02^{2-} P$-Value is 0.045 & 90 \\
\hline
\end{tabular}

Efficiency of inhalable pollutant particle collection has increased $(P-$ Value $<0.05)$ with the increase of the flow rate. Also, with increase in the flow rate, collection efficiency of particles increases $(P-$ Value $<0.05)$.

\section{B. Mathematical Modeling}

From the simulation experimentations, the residuals does a very good job of converging at approximately 2460 iterations at inlet velocities of $11.176 \mathrm{~m} / \mathrm{s}$ as shown in Fig. 1. Graphic displays of the velocity, pressure and turbulent fields which includes velocity, pressure and turbulent contours describing the gas flows from the inlet, across the scrubbing camber to the outlet for the inlet velocities considered in the study is shown in Fig. 2 - Fig. 4 respectively.

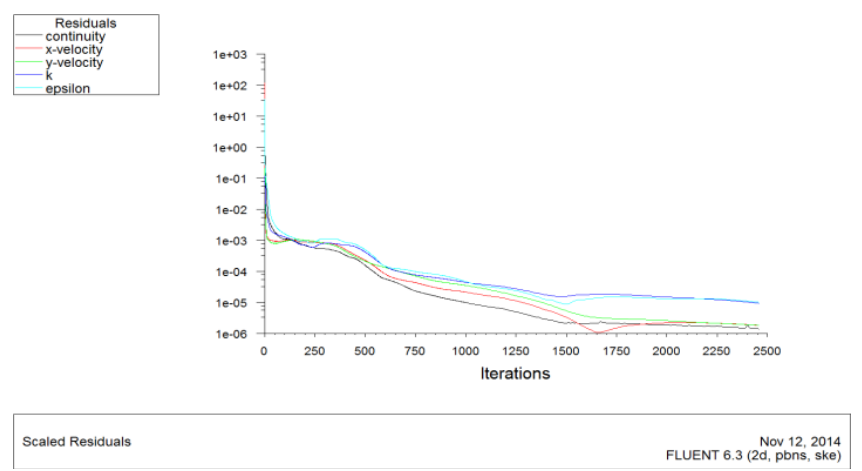

Fig. 1. Residuals for the continuity, k-epsilon and X, Y velocities at $11.176 \mathrm{~m} / \mathrm{s}$.

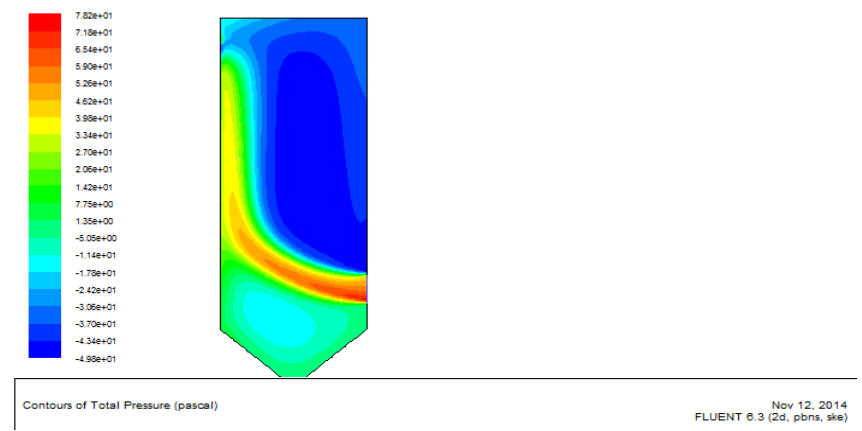

Fig. 2. Contours display of the pressure total the scrubber at $11.176 \mathrm{~m} / \mathrm{s}$.

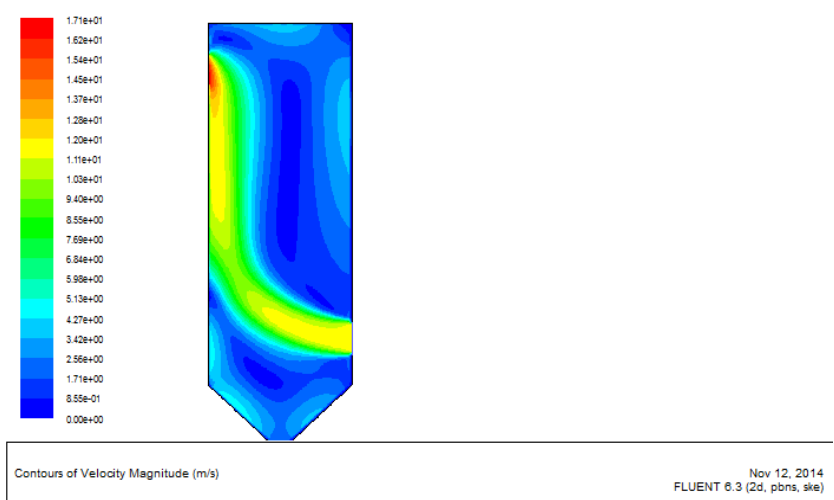

Fig. 3. Contours display of the velocity magnitude the scrubber at $11.176 \mathrm{~m} / \mathrm{s}$.

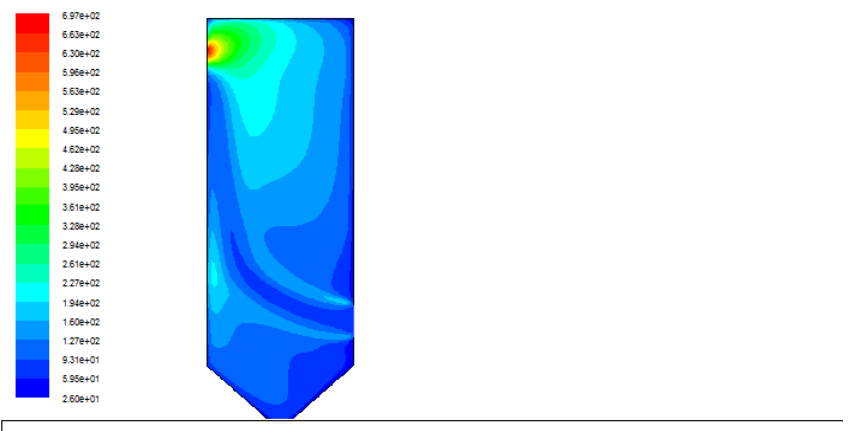

Contours of Turbulent Intensity (\%)

Nov 12,2014
ELUENT 03 (20, pbrs, ske)

Fig. 4. Contours display of the turbulent intensity the scrubber at $11.176 \mathrm{~m} / \mathrm{s}$.

\section{CONCLUSIONS}

In this study, an analytical method for design and 
prediction of spray tower scrubber performance based on silica dust particle removal efficiency has been described. The approach focused on the design of a scrubber system in according to ACGIH recommended for the collection of dust particle and results of CFD simulation [6], [11]. The liquid flows of $11.4 \& 20.3 \mathrm{~L} / \mathrm{min}$ ACGIH recommended were used to investigate in give the optimum result for the performance of the system [6], [11]. With the increase of water flow, the collection efficiency of inhalable and non-inhalable silica particles has increased. With the increase of flow rate the contact of water droplets with pollutant has increased, and the reason of efficiency increase of particle collection is the increase of particle contact with the water droplets. On the other hand, with the increase of water flow the diameter of the water droplets from the nozzles has become smaller; therefore, the contact of the particles with the water droplets increased. Therefore, it can be said that with the increase of liquid flow rate, first the amount of water sprayed on the particles will become more, second the diameter of droplets become smaller. Janas \& Mason found out in their experiments that whenever the diameter of the sprayed droplets becomes less, the efficiency of particle collection increases. Both factors increase the efficiency. This result can be compared with the results obtained by Kati Varaslahti (2002). In her experiments, she measured the collection efficiency of particles in the three flows rates $7.5,10$, and 12.5 liters per minute. He discovered that collection efficiency of particles increases with the increase of flow rate [12].A computational fluid dynamics simulation for the calculation of pressure drop, velocity and turbulent of wet scrubbers has been developed and comparison against ACGIH recommended [13]. Pressure drop and velocity data for a spray tower scrubber obtained from a numerical simulation are presented. Numerical results are in good agreement with ACGIH recommended [14]. The CFD simulation results demonstrate the distribution of the velocity $\&$ pressure of the spray tower scrubber. Based on the results, optimal design of the equipment set-up can be realized that is according to ACGIH recommended [15]. Factors such as the dust particle properties, generation of the dust particles in the scrubber system, liquid droplets and spray nozzle and atomization analysis were not considered. It is expected that the information provided in this paper will be useful for engineers and researchers for many air pollution control applications especially in the areas of particulate matter $\left(\mathrm{PM}_{10}\right)$ emissions [11].

In general, the CFD simulation can improve efficiency, reduce cost, and shorten experimental periods. It can also provide insights for optimal equipment design [15]. With the increase of water flow rate the collection efficiency of inhalable and non-inhalable particles of silica particles increases. This is due to the increase of surface contact of water droplets with pollutant, which has caused the efficiency of the system. Future work should concentrate on an improved prediction of droplet size distribution in order to enhance dust-capturing calculation [14].

\section{REFERENCES}

[1] N. Nevers, Air Pollution Control Engineerin, 2nd ed., Victor Hugo, 2013, ch. 4, pp. 132-134.

[2] Q. L. Yu, "Indoor air quality improvement applying photocatalytic oxidation: A computational fluid dynamics modeling approach".

[3] M. Pontiggia, "Hazardous gas releases in urban areas: Assessment of consequences through CFD modelling," 2010.

[4] Canadian Centre for Occupational Health and Safety, Silica, November, 1998.

[5] L. K. Wang, N. C. Pereira, and Y. T. Hung, Air Pollution Control Engineering, 1st ed, Totowa, New Jersey: Humana Press, 2004, ch. 5, pp. 197-198.

[6] American Conference of Governmental Industrial Hygienists (ACGIH), Industrial Ventilation: A Manual of Recommended Practice, 25th Edition, 2004.

[7] L. Theodore, Air Pollution Control Equipment Calculations, 1st ed, John Wiley \& Sons, Inc, 2008, ch. 7, pp. 214-216.

[8] B. A. Danzomo, "CFD based parametric analysis of gas flow in a counter-flow wet scrubber system," International Journal of Environmental Protection and Policy, vol. 1, no. 2, pp. 16-23, 2013.

[9] S. Singh. CFD Simulation of benzene-toluene system over sieve tray. (2012). [Online]. Available: www.ijeset.com/media/10N5-IJESET0106404.pdf

[10] W. A. Burgess, M. J. Ellenbecker, and R. D. Treiman, Ventilation For Control of the Work Environment, 2nd ed, Wiley, 2004, ch. 3, p. 109.

[11] B. A. Danzomo, "Performance evaluation of wet scrubber system for industrial air pollution control," ARPN Journal of Engineering and Applied Sciences, 2012.

[12] K. Vaaralati and A. Laitinen, "Spray charging of droplets in a wet scrubber," Air \& Waste Manage. Assoc., no. 52, pp. 175-180, 2002.

[13] C. Goniva, "Simulation of gas scrubbing by a combined eulerian-lagrangian model," presented at Seventh International Conference on CFD in the Minerals and Process Industries, CSIRO, Melbourne, Australia, December 9-11, 2009.

[14] M. Toledo-Melchor, Numerical Simulation of Flow Behavior within a Venturi Scrubber, Hindawi Publishing Corporation Mathematical Problems in Engineering, p. 7, 2014.

[15] S.-H. Li, "CFD simulation on performance of new type umbrella plate scrubber," Trans. Nonferrous Met. Soc., vol. 18, pp. 488-492, 2008.

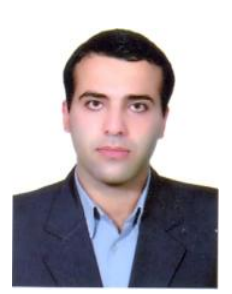

Majid Bayatian was born in Tehran on August 8, 1982. He got his M.Sc. degree in occupational health at Hamedan University of Medical Sciences (HUMS) in 2008. He is a PhD student of occupational health at Shahid Beheshti University of Medical Sciences. His current research interests are air pollution control and air pollution simulation. $\mathrm{He}$ is an author of 5 publications. His previously published works contain investigation studies about safety, accident related work and indoor air pollution control and simulation. 